\title{
CUENCA BAJO EL CACIQUISMO: ELECCIONES Y PODER POLÍTICO (1903-1907)
}

\author{
Alfredo GÓMEZ MARTíNEZ - Universidad de León \\ María Dolores PERALES PovedA - Universidad de Alicante
}

\begin{abstract}
RESUMEN: Durante la primera década del siglo XX se experimenta una evolución en la concepción política de la España de la Restauración. Los líderes nacionales, Maura y Canalejas, desarrollarán una serie de planteamientos destinados a modernizar la práctica política. A través del estudio de las elecciones de 1903, 1905 y 1907 en la provincia de Cuenca, se va a analizar si la actividad y dinámica de la política durante esta época presenta unas características modernas o, si por el contrario, persiste un comportamiento político arcaico basado en el caciquismo.
\end{abstract}

PALABRAS CLAVE: Restauración, elecciones, Cuenca, caciquismo.

ABSTRACT: During the first decade of the twentieth century, an evolution in the political view of Spanish Restoration's age is experienced. The national leaders, Maura and Canalejas, are going to develop a series of formulations in order to modernize the political practice. Through the study of the elections in 1903, 1905 and 1907 in the province of Cuenca, it is going to be analyzed whether the activity and the dynamics in policy in this time present modern characteristics or, on the contrary, it persists an archaic political behaviour based on cacique's domination and influence.

KEYWORDS: Restoration, elections, Cuenca, cacique.

\section{INTRODUCCIÓN}

Sobre la etapa histórica de la Restauración se han publicado en los últimos años excelentes balances historiográficos, donde se constatan diversas aportaciones que, desde la perspectiva local y regional, han permitido conocer las raíces sociales del poder, es decir la inserción de los intereses del grupo de poder en la política. Gracias a este tipo de investigaciones que aportan suficientes elementos de información, hoy se pueden poner en duda algunas visiones más generales y tópicas sobre el sistema, profundizando en algunos aspectos esenciales e incorporando importantes matizaciones. Sobre Castilla-La Mancha, se cuenta con diversos trabajos locales acerca del poder político en la Restauración, entre los que destacan los de Moreno Luzón para Guadalajara, Barreda (Ciudad Real) o el de Panadero sobre la estructura poblacional de Albacete, existiendo, sin embargo, un 
vacío en este tipo de estudios para la provincia de Cuenca. Por consiguiente, el presente trabajo tiene por objeto analizar, a través de las elecciones generales de 1903, 1905 y 1907, la dinámica del poder político en la provincia de Cuenca, estableciendo la relación existente entre el centro y la periferia, es decir la conexión entre el poder central y los poderes locales en esta provincia castellano-manchega, y al mismo tiempo, poner de manifiesto la coyuntura política de la España restauracionista, en la que la desmovilización de la ciudadanía permitía a las elites dinásticas asentar sin dificultad su control y eliminar la competencia electoral. No obstante, durante la primera década del siglo XX, coincidiendo con el inicio del reinado de Alfonso XIII, se experimenta una evolución en el concepción política. Los líderes nacionales, Maura y Canalejas, desarrollarán una serie de planteamientos destinados a modernizar la práctica política. Por este motivo, hemos considerado interesante analizar en el caso conquense si la actividad y dinámica de la política durante la primera década del siglo XX presenta las características de esta etapa modernizadora o, si por el contrario, persiste un comportamiento político arcaico basado en la influencia ejercida por los caciques locales.

Al objeto de explicar el nivel de articulación del poder político en la provincia de Cuenca, hemos estructurado nuestro trabajo en tres apartados. En el primero explicamos, a partir de diversas fuentes estadísticas y bibliográficas, la estructura socioeconómica conquense como elemento clave en la actividad política de dicha provincia. Un segundo epígrafe lo dedicamos a describir el mapa político electoral, explicando la articulación de los partidos políticos como instrumentos del sistema canovista para el ejercicio del poder, mediante fórmulas de representación que limitarían la participación electoral y una ley electoral, la de 1890, que a pesar de tener un contenido reformista al introducir el sufragio universal masculino y toda una serie de mecanismos para el fomento de la transparencia electoral, no consiguió ni que la participación electoral fuese de las proporciones que se esperaban de una extensión de derecho al voto tan importante en el contexto de la época, ni tampoco la erradicación del fraude en los procesos electorales. En el tercer apartado, analizamos los tres procesos electorales de 1903, 1905, y 1907 para estudiar la relación existente entre el poder central y el local y la utilización del sistema de turno como elemento primordial.

El presente estudio, lo hemos elaborado a partir de fuentes inéditas consultadas en los Archivos de la Fundación Antonio Maura (A.M.) y Archivo Histórico Nacional en Madrid (A.H.N.), en el Archivo Juan de La Cierva en Murcia (A.C.),y en el Archivo de la Diputación Provincial de Cuenca (A.D.P.C). 


\section{ESTRUCTURA SOCIO-ECONÓMICA DE CUENCA: UNA SOCIE- DAD AGRARIA Y ANALFABETA}

Cuenca era una provincia que compartía muchas de las características típicas de la España interior, como pasaba con el resto de las provincias castellanomanchegas, "marcada por el peso del mundo rural y por su cercanía a Madrid", la capital. Su vida política se situaba dentro de este marco socio-económico y geográfico y se desarrollaba "en un medio desmovilizado y dominado por las elites profesionales y agrarias que componían los partidos monárquicos de turno"1. En el caso conquense, diversas facciones destacaron en política, siendo una elite que conformaba un grupo estrechamente ligado a la propiedad de la tierra, herencia a menudo de los diferentes procesos de desamortización, y en menor medida adecuado a otros perfiles profesionales como los de abogado, periodista o ingeniero. Así, se pueden encontrar en las lista electorales de 1907 a los representantes y a sus familias contribuyendo con grandes cantidades de dinero por tener propiedades agrarias. Por ejemplo en Cuenca, Pedro José Cobo, diputado en 1903 y senador de la provincia, era el máximo contribuyente del municipio ${ }^{2}$.

En un medio ruralizado como era Cuenca su economía agraria estaba basada en la producción cerealera, vitivinícola y de secano, y en un cierto aprovechamiento de los recursos forestales. Se podían encontrar unas pocas zonas industriales, que se limitaba a la industria minera. Por tanto, la estructura social castellanomanchega en general, y conquense en particular, encontraba su principal clave explicativa en la distribución de la propiedad de la tierra. Existían a comienzos del siglo XX dos tipos de propiedad agraria: la zona del sur (San Clemente y Motilla del Palancar), donde abundaban las grandes fincas y la masa jornalera conformaba la mayoría de población; y la zona del norte y centro (Cañete, Cuenca, Huete y Tarancón), en la que destacaba el pequeño campesinado y la explotación de la pequeña propiedad. Esto era condicionado por la concentración demográfica que existía en los pueblos meridionales, a diferencia de los del norte, donde la dispersión aldeana era la forma de vida.

\footnotetext{
1 Moreno Luzón, J. (2001). «Castilla-La Mancha», en VArela OrTEGa, J. (Director). El poder de la influencia. Geografia del caciquismo en España (1875-1923). Madrid: Marcial Pons y Centro de Estudios Políticos y Constitucionales, p. 151.

${ }^{2}$ González Calleja, E. y Moreno Luzón, J. (1993). Elecciones y Parlamentarios. Dos siglos de historia en Castilla-La Mancha. Castilla-La Mancha: Junta de Comunidades de Castilla-La Mancha, Cortes de Castilla-La Mancha, pp. 212-213.
} 
Frente a la supremacía rural, la capital resultaba ser pequeña como núcleo poblacional y económico ${ }^{3}$. A pesar de ello, en la provincia de Cuenca se produce a principios del siglo $\mathrm{XX}$ un trasvase de población hacia la capital y a otras localidades de la provincia con un mayor número de habitantes. Era un proceso con cierta lógica, ya que la población conquense era en su mayoría dispersa ${ }^{4}$ ( en el año 1900 había un total de 288 ayuntamientos, 3 ciudades, 175 villas, 112 lugares, 58 caseríos y 16161 edificios y albergues aislados $)^{5}$.

En cuanto al número de habitantes en Cuenca, hay que hacer una diferenciación entre la población provincial y la población urbana. Hasta el último cuarto del siglo XIX la situación es siempre la misma: se va produciendo un progresivo aumento poblacional en la provincia, mientras que en la capital el fenómeno es el contrario, tiene lugar un constante retroceso. Pero para los años de nuestro estudio, la evolución provincial sigue siendo la misma, mientras que en la capital conquense ya no hay un retroceso de la población sino que, como se puede observar en el Cuadro 1, se va produciendo también un progresivo aumento. A pesar de ello, sólo un $4,3 \%$ del total de la población provincial es población urbana ${ }^{6}$. Y este crecimiento, según Miguel Ángel Troitiño, es debido a la llegada de emigrantes que se desplazan principalmente de localidades de la provincia, además de la alta tasa de natalidad, que es frenada por la elevada mortalidad. Por tanto, "a pesar del crecimiento natural negativo, el incremento es positivo gracias al favorable saldo migratorio"" .

En cuanto a la composición socioprofesional de la población hay que decir que, fueron escasos los cambios durante los diez primeros años del siglo XX. La población activa de la provincia era, aproximadamente, del 35\%. De dicha parte, un $85 \%$ se dedicaba a la agricultura, un 8 por ciento a la industria, el 2 por ciento a

3 Moreno LuZÓn, J. (2001). «Castilla-La Mancha»..., p. 152.

${ }^{4}$ López Villaverde, A. L. y SÁnchez SÁnchez, I. (1998). Historia y evolución de la prensa conquense (1811-1939). Cuenca: Ediciones de la Universidad de Castilla-La Mancha, p. 51.

${ }^{5}$ Nomenclátor de las ciudades, villas, lugares, aldeas y demás entidades de población de Cuenca formado por la Dirección General del Instituto Geográfico y Estadístico con referencia al 31 de diciembre de 1900. Madrid, 1904.

${ }^{6}$ Lopez Villaverde, A. L. y Sanchez Sanchez, I. (1998). Historia y evolución de la prensa..., pp. 49-50.

${ }^{7}$ Troitiño VinUeSA, M. A. (1984). Cuenca: Evolución y crisis de una vieja ciudad castellana. Madrid, p. 243. 
los transportes y el comercio, y el 5 por ciento a los servicios ${ }^{8}$. Es decir, la agricultura era la fuente principal de la economía. Por esta razón, las elites provinciales estaban vinculadas a la propiedad de la tierra en toda la provincia, además de estar relacionadas con las profesiones vinculadas a la Administración pública (política, judicial o militar ). Sin embargo, la estructura centralizada del Estado y la proximidad a Madrid hacían que en ocasiones la capa superior de estas elites estuviera ausente, aunque en Cuenca, según el análisis de los documentos, se puede llegar a la conclusión de que la elite local tenía más poder ${ }^{9}$. Estas elites experimentan un proceso de cambio en el tránsito del siglo XIX al XX. Aparece una nueva oligarquía terrateniente, como los diputados a Cortes por Cuenca y Huete (Cobo y Sartorius ${ }^{10}$ ), cuyo poder surge de las compras de tierras y de la especulación y el préstamo, lo que aprovechan para conseguir poder político ${ }^{11}$.

Cuadro 1: Evolución de la población en la provincia de Cuenca (1900-1910)

\begin{tabular}{rrrr}
\hline Año & Capital & Provincia & Total \\
\hline 1900 & 10.756 & 238.940 & 249.696 \\
1901 & 10.804 & 239.852 & 250.696 \\
1902 & 10.897 & 241.692 & 252.589 \\
1903 & 10.991 & 243.596 & 254.537 \\
1904 & 11.086 & 245.414 & 256.500 \\
1905 & 11.182 & 247.296 & 258.478 \\
1906 & 11.278 & 249.193 & 260.471 \\
1907 & 11.375 & 251.105 & 262.480 \\
1908 & 11.473 & 253.031 & 264.504 \\
1909 & 11.571 & 254.973 & 266.544 \\
1910 & 11.721 & 257.913 & 269.634 \\
\hline
\end{tabular}

FUENTE: Censos de Población e Indicadores Sociales y Económicos de España, 19001990.Madrid, 1991.Elaboración propia.

${ }^{8}$ Lopez Villaverde, A. L. y SAnChez Sanchez, I. (1998). Historia y evolución de la prensa..., pp. 52-53.

${ }^{9}$ Moreno Luzón, J. (2001). «Castilla-La Mancha»... p.152.

${ }^{10}$ Es el segundo Conde de San Luis. Políticamente figuró en las filas del conservadurismo datista, del que durante años fue el principal líder de la provincia de Cuenca. Dominó de forma absoluta el distrito de Huete, por lo que obtuvo el acta de diputado al Congreso en doce ocasiones entre 1896 y 1921. Se le llegó a conocer como "el gran señor de Cuenca".Ver Priego SÁnChez-Morate, H. y Silva Herranz, J. A. (2002). Diccionario de personajes conquenses (nacidos antes del año 1900). Cuenca: Diputación Provincial, pp. 351-352.

${ }^{11}$ García Marchante, J. S. y López Villaverde, A. L. (Coords.) (1997). Relaciones de poder en Castilla: El ejemplo de Cuenca. Cuenca: Universidad de Castilla-La Mancha, p. 260. 
España contaba, durante la primera década del siglo XX, con unos 19 millones de habitantes, de los cuales alrededor del $60 \%$ eran analfabetos. Esta cifra tan elevada se da también en Castilla-La Mancha, donde cabría destacar, como se puede apreciar en el Cuadro 2, la pobre evolución que se produce en estos diez años. Llama la atención el bajo porcentaje de analfabetismo que hay en la provincia de Guadalajara, feudo del liberal Conde de Romanones, en comparación con el resto de las provincias castellano-manchegas, además del alto porcentaje de mujeres analfabetas, alrededor del $80 \%^{12}$.

Cuadro 2. Porcentajes de analfabetismo en Castilla-La Mancha (1900-1910)

\begin{tabular}{lrrrr}
\hline & \multicolumn{3}{c}{1910} \\
\cline { 2 - 5 } \multicolumn{1}{c}{ Provincia } & $\%$ Hombres & $\%$ Mujeres & \% Hombres & $\%$ Mujeres \\
\hline Albacete & 67,23 & 83,30 & 67,78 & 81,98 \\
Ciudad Real & 64,31 & 79,97 & 66,28 & 80,41 \\
Cuenca & 60,56 & 80,26 & 59,55 & 78,44 \\
Guadalajara & 38,45 & 66,00 & 43,60 & 65,42 \\
Toledo & 59,51 & 74,68 & 60,83 & 73,75 \\
\hline
\end{tabular}

FUENTE: Censo de la población de España en 1900. Tomo III, Madrid, 1907; y Censo de la población de España en 1910. Tomo II, Madrid, 1916. Elaboración propia.

En Cuenca, durante esta década, los índices de analfabetismo también son muy altos, alrededor del 70 por ciento de la población era analfabeta. En la capital ese índice disminuye ligeramente, aunque en la primera década del siglo XX hay un pequeño aumento, quizás debido al "trasvase de población a la capital". Este caso también se da en otro de los distritos de la provincia, Tarancón, al contrario que en los restantes distritos (Cañete, Huete, Motilla del Palancar y San Clemente), donde el alto nivel de analfabetismo va disminuyendo a medida que avanza este primer decenio. A pesar de los altos niveles de analfabetismo, las publicaciones periodísticas eran continuas, con la creencia de que se podía llegar a amplias capas de la población. La realidad era otra ${ }^{13}$.

Encontramos, por tanto, en el analfabetismo, una de las claves de la desmovilización popular en los procesos electorales. Para la elite política esto

12 Ver Censo de la población de España en 1900. Tomo III, Madrid, 1907; y Censo de la población de España en 1910. Tomo II, Madrid, 1916.

13 Lopez Villaverde, A. L. y SAnChez Sanchez, I. (1998). Historia y evolución de la prensa..., pp. $48-53$. 
implicaba una escasa preparación del pueblo para la política ${ }^{14}$.

\section{EL MAPA POLÍTICO-ELECTORAL CONQUENSE}

Hasta 1890, liberales y conservadores tienen en común la consecución de intereses personales, es decir, la ocupación de puestos administrativos en beneficio de sus propios cuadros y de sus correligionarios, pero partir de esta fecha, dos nuevos factores diferenciarán a liberales y conservadores. El primero fue la reimplantación del sufragio universal masculino, que obligó a que en los ámbitos urbanos, los partidos tuvieran que ir modernizando sus estructuras para competir con las fuerzas antidinásticas. Por otro lado, el sistema de turno propició en algunas provincias la creación de jefaturas provinciales que favorecería una mejor articulación de los partidos.

Los Liberales, tras la caída del último gabinete de Sagasta, se plantearon el doble problema de dar un nuevo programa al partido, y designar un nuevo jefe que sustituyese al carismático candidato. En 1902, se hizo público el manifiestoprograma, conteniendo los puntos de vista de la fracción más radical dentro del partido liberal, y junto con declaraciones que son simple repetición de fórmulas tradicionales como la defensa de los derechos individuales o la independencia del poder judicial, el programa se centra en tres cuestiones fundamentales: en primer lugar la movilización de los electores, para lo que en la primera versión, se piensa incluso en recurrir a la obligatoriedad del voto, además establecer la libertad de asociación aunque para constituirse las sociedades quedarían sometidas a las leyes comunes en todo lo relativo a sus fines temporales y por último, poner fin al impuesto de consumo, abaratar los artículos de primera necesidad, fomentar cooperativas de consumo y producción, favorecer las sociedades de previsión y regular mediante la Ley los contratos de trabajo ${ }^{15}$. Puede verse en estas medidas, que el partido liberal, empieza en la primera década del siglo XX, a adquirir un carácter mucho más avanzado y reformista, próximo a la realidad social, nutriéndose del pensamiento del nuevo liberalismo europeo.

En el partido conservador, resultó clave la figura del político Antonio Maura, cuyo proyecto se centró en la reorganización del conservadurismo en el ámbito local, al objeto de, a largo plazo, obtener el control del partido. La reorganización

${ }^{14}$ Jover ZAMORA, J. M. (1981). «La época de la Restauración. Panorama político y social, 18751902», en TuÑón De LaRA, M. (Dir.). Historia de España. Vol. VIII. Barcelona, pp. 269-406.

15 Artola, M. (1974). Partidos y programas políticos. 1808-1936. vol 1. Madrid: Aguilar, p. 353. 
se vio favorecida por el cambio generacional que las propias limitaciones biológicas imponían y se tradujo en la aparición de nuevas elites de partido que fueron captadas por el maurismo.

El grupo parlamentario, el comité electoral y la redacción del periódico eran los tres elementos cuya reunión daba origen a un partido político. La prensa seguía con detalle las negociaciones del encasillado y especulaba sobre los nombres que se barajaban en cada circunscripción. El comité constituido en Madrid, para liberales y conservadores, sería la pieza clave, puesto que aglutinaba a los principales dirigentes nacionales, aunque lo que definía a ambas formaciones eran sus respectivos grupos parlamentarios. Así, aunque en 1875 los Círculos Alfonsinos aparecieron como el primer eslabón entre los poderes locales y el Gobierno, no fue hasta la Constitución de las Cortes de 1876 cuando empezaron a formarse comités conservadores en las provincias, de esta manera, los partidos políticos se crearon por penetración territorial, es decir, el centro controló y dirigió el desarrollo de la periferia $^{16}$. En las provincias, la capital actuaba como centro difusor. El jefe de partido era nombrado en virtud de dos poderes: por un lado, debía contar con el apoyo del comité central, por lo que el respaldo del jefe nacional indicaba que el político en cuestión estaba insertado en una clientela política; por otra parte el jefe nacional elegía a quien demostrase tener más fuerza entre los notables provinciales. De esta manera, la injerencia gubernamental en los comicios, tenía la forma de una pirámide, cuya cúspide se hallaba en Madrid y disponía de contactos estrechos con el liderazgo nacional de una de las grandes organizaciones partidistas de la época, sus jefes, los grandes caciques, ocupaban un escaño en el Senado y controlaban uno o más distritos electorales en una provincia.

Como señala Tusell, el carácter poco moderno de los partidos políticos del turno, queda de manifiesto no sólo por su carencia de organización, su dependencia de la capital de la nación respecto a la elección del jefe provincial o la ausencia de afiliados, sino por el hecho de que el principal coagulante de su unidad sea precisamente el favor ${ }^{17}$. El localismo y la carencia de ideología en la lucha política, convertía a los partidos del turno en un conglomerado de facciones de notables seguidos de sus clientelas en busca de favores. Todo tipo de reclamaciones e intereses buscaban el favor privado gestionado por un notable como vía de presentación, de modo que la representación de las estructuras político-clientelares de lo partidos de turno sirvió para satisfacer las demandas sociales, que quedarían

\footnotetext{
${ }^{16}$ Ibidem, pp 178-181.

${ }^{17}$ Tusell, J. (1976). Oligarquía y caciquismo en Andalucía (1890-1923). Barcelona: Planeta, p.
} 349. 
representadas, no a través de los partidos organizados de acuerdo con aquellos, sino mediante la acción de los múltiples agentes individuales ${ }^{18}$.

Así pues, con la consolidación de los Estados liberales, los partidos políticos se convirtieron en el cauce privilegiado para ejercer el poder político, y su evolución durante la pasada centuria estaría determinada por las características propias del sistema electoral. Éste, limitó la participación de una parte de la sociedad, mediante fórmulas de representación que, a partir de una división territorial que en su mayoría establecía distritos uninominales ${ }^{19}$, es decir unidades espaciales de influencia, propició que desde las décadas de los años ochenta y noventa del siglo XIX, estas unidades fuesen el elemento fundamental par el asentamiento de los grandes cacicates, prueba de ello fue la creación de los denominados distritos propios, aquellos en los que un mismo diputado o distintos diputados de una misma facción política eran elegidos en cinco o más elecciones, aún al margen del turno. En el caso de Castilla la Mancha, podemos apreciar la evolución de la influencia ejercida en los distritos uninominales, como se puede observar en el Cuadro 3.

Cuadro 3: Los distritos propios en Castilla-La Mancha (1901-1923)

\begin{tabular}{lrrr}
\hline \multicolumn{1}{c}{ Provincia } & Distritos & Propios -1901 & Propios -1923 \\
\hline Albacete & 5 & 1 & 2 \\
Ciudad Real & 6 & 2 & 1 \\
Cuenca & 6 & 2 & 4 \\
Guadalajara & 5 & 2 & 3 \\
Toledo & 8 & 4 & 4 \\
\hline Total. & 30 & 11 & 14 \\
\hline
\end{tabular}

FUENTE: MORENO LUZÓN, J. (2001). «Castilla-La Mancha»..., p. 159. Elaboración propia.

Quizás sea en la elección del Senado donde mejor quede representado el poder político de las elites. En la elección para el Senado de 1907 en España era el rey y las provincias, es decir, las elites provinciales, quienes elegían un mayor número de senadores. Sólo 53 de 360 salían elegidos por derecho propio. Además, hay que resaltar que las corporaciones (Arzobispados, Reales Academias, Universidades y las Sociedades económicas) tenían un cierto poder político ${ }^{20}$.

18 Varela Ortega, J. (1977). Los amigos políticos. Partidos, elecciones y caciquismo en la Restauración (1875-1900). Madrid: Alianza Editorial, p. 565. Veáse también WeBER, M. (1984). Economía y Sociedad: esbozo de Sociología comprensiva. Méjico, pp. 228-229 y 1078-1079.

19 Zurita Aldeguer, R. (1996). Notables, politicos y clientes: La política conservadora en Alicante, 1875-1898. Alicante: Instituto de Cultura Juan Gil Albert, p. 76.

${ }^{20}$ AM, leg. 484/20, composición legal del Senado en Abril de 1907. 
La provincia de Cuenca conforme con la Ley electoral de 1878, se organizó en seis distritos electorales: Cañete, Cuenca, Huete, Motilla, San Clemente y Tarrancon.

El partido liberal estuvo representado por Juan Correcher, un hombre hecho así mismo desde un origen humilde, que a través del negocio de la madera se hizo rico y propietario de montes en la serranía. Correcher, tras pasar por las filas de Romero Robledo, se integró en el liberalismo y acabó en el grupo del conde de Romanones.

En el caso conquense, el maurismo dispuso en toda la provincia de fuerzas mayoritarias a partir de la incorporación del grupo gamacista, escindido del Partido Liberal siguiendo a su jefe nacional, Antonio Maura, a quien los nuevos dirigentes conservadores, profesaron lealtad, fundamentada en la propia amistad personal o vinculación familia. Este tipo de relación, en el caso de Cuenca, se observa a partir de la correspondencia personal entre políticos como Mariano Catalina y Antonio Maura.

Entre las figuras claves del conservadurismo conquense, hay que destacar a la tradicional familia Sartorius, con arraigo desde la época Isabelina. Fernando Sartorius, segundo Conde de San Luis, figuró en la Restauración al frente del partido conservador. También contaron en la provincia los conservadores con mauristas entre los que destacan, Mariano Catalina y Francisco Martínez Contreras. En cuanto a los procedentes del gamacismo, nos podemos encontrar con caciques conservadores como el conde de Retamoso o la familia Casanova ${ }^{21}$. (Ver Organigrama 1).

Junto con los partidos de turno actuaron también las fuerzas políticas situadas en los márgenes del sistema. En Castilla-La Mancha, los carlistas tuvieron cierta importancia en zonas como Guadalajara o Ciudad Real, pero carecieron de capacidad movilizadora para retar a los caciques dinásticos en la provincia de Cuenca.

El proyecto republicano buscaría sacar a España del "marasmo" al que la había conducido el carácter "patrimonial" de la Monarquía, restableciendo la soberanía nacional mediante la afirmación de los derechos del ciudadano y la marginación de los poderes tradicionales asociados a la Iglesia y a la burguesía conservadora ${ }^{22}$. En las capitales de provincia y algunos pueblos grandes no faltaron los comités y las

${ }^{21}$ Moreno LuZÓn, J. (2001). «Castilla-La Mancha»..., pp. 154-155.

22 SuARez CORTINA (2000). El gorro frigio, liberalismo, democracia y republicanismo en la Restauración. Madrid: Biblioteca Nueva, p. 20. 
publicaciones de los republicanos sin embargo en Castilla la Mancha, salvo en Toledo, donde contaron con figuras de la talla de Julián Besteiro o Luis de Hoyos, los republicanos, como en el resto de España se mostraron profundamente divididos y obtuvieron representación en las Cortes en contadas ocasiones ${ }^{23}$.

Organigrama 1: Fuerzas politicas en Cuenca. Redes clientelares (1876-1923).
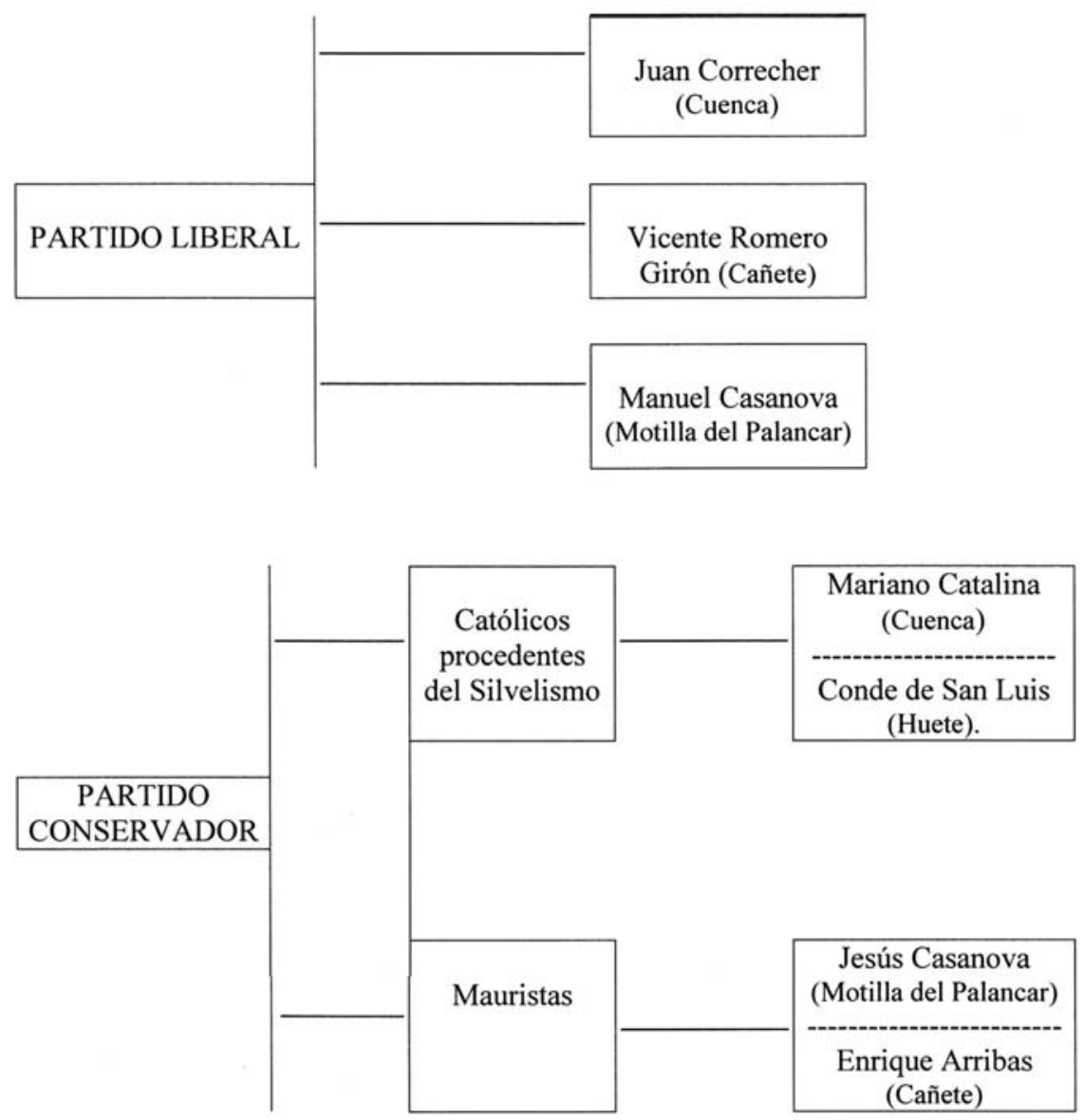

FuENTE: MORENO LuZÓN, J. (2001). «Castilla-La Mancha...», pp. 154-155. Elaboración propia.

${ }^{23}$ Ibidem, p. 157. 
En 1890 el partido liberal va a aprobar una nueva Ley electoral. La naturaleza reformista de la Ley electoral de 1890 respecto a la primera Ley electoral de la Restauración, 1878, hay que entenderla, en primer lugar, por la reinstauración del sufragio universal masculino, y en segundo lugar, por las reformas que introduce en el procedimiento electoral.

Mediante el sufragio universal masculino se concedió el derecho al voto a todos los varones seglares mayores de 25 años, que acreditasen dos años de residencia en el municipio, no sin los evidentes recelos de la oposición conservadora, por los riesgos que implicaba para las mayorías monárquicas, al dar mayor representación a las oposiciones políticas ajenas al sistema, por ello y pese a la promesa de respetar y cumplir la Ley, se señaló la intención de rectificarla si llegaba a ser "un peligro para la instituciones o un mal para el país ${ }^{24}$.

Lo que fuera en la práctica esta Ley dependía del procedimiento electoral, y de las garantías en la misma que preservasen la transparencia electoral. La nueva Ley, suponía mayores precauciones formales para garantizar la correcta formación del censo electoral. Para su "formación, revisión y custodia" se creaba la Junta Central integrada por el presidente del Congreso, y ex presidentes y vicepresidentes has un número de 15; las Juntas Provinciales con las mismas categorías anteriores en las Diputaciones más cuatro diputados en ejercicio elegidos por la propia Diputación y las Juntas Municipales integradas por miembros del Ayuntamiento y ex Alcaldes ${ }^{25}$. Los Ayuntamientos, tomando como base el padrón eran los encargados de formar las listas electorales, y la Junta Municipal, donde aquel era mayoritario, recibía e informaba las reclamaciones de los excluidos, sobre las que decidía la Junta Provincial. En caso de desacuerdo el reclamante podía recurrir a la Audiencia Territorial, que si estimaba temeraria la apelación podía condenar a costas al demandante. La composición de las juntas provinciales y municipales no satisfizo a las oposiciones puesto que no veían en ellas suficientemente garantizada la representación de las minorías, ya que dejaba el control del censo en manos de autoridades políticas y locales y provinciales, tradicionalmente responsables de la falsificación de los elementos electorales. En la práctica eran los ayuntamientos los que confeccionaban las listas electorales, las reclamaciones eran recogidas por la Junta Municipal del Censo en la que tenía mayoría el Ayuntamiento y decidía la provincial. Todo esto suponía que partidos y candidatos tuviesen un enorme interés

24 Garrido Martín, A. (2000). «La Reforma electoral de 1890», en MALAmUd, C. (coord..). Legitimidad, representación y alternancia en España y América latina: las reformas electorales (1880-1930). F. C. E. de Méjico, p. 44.

25 Ibidem, p. 45. 
en controlar los ayuntamientos y la Diputación antes de las elecciones generales. Otro aspecto fundamental de la Ley, era el relativo a las mesas electorales. En cada sección estarían integradas por un presidente ( el Alcalde, los tenientes de Alcalde o concejales, por su orden si hubiera más de una sección en el ámbito municipal) y los interventores - otra de las novedades introducidas- nombrados por los candidatos y la Junta Provincial (dos para cada sección del distrito). La mesa presidía la votación y realizaba el escrutinio ${ }^{26}$.

Podemos llegar a la conclusión, que en la mesa electoral estaba la clave de las elecciones. Su constitución legítima representaba la garantía de validez del sufragio, pero en el caso contrario, tanto su constitución como la gestión del Presidente, por su influencia en el desarrollo de las elecciones ofrecería mayores posibilidades de fraude. En la práctica, la mayoría de incidentes y fraudes ocurridos durante las elecciones, especialmente en poblaciones pequeñas estuvieron relacionados con la composición y actuación de las mesas electorales.

En lo referente a la división del territorio, esta Ley mantiene la provincial de 1871, modificada algo en la Ley electoral de 1878, estableciendo distritos pequeños y perfectamente controlables ${ }^{27}$

El sufragio universal masculino por la ley electoral de 1890, no sólo no causó un significativo incremento de la participación electoral, sino que su efecto supuso más bien una mecanizada lucha que derivó en un acusado fraude electoral. Las elecciones en España por tanto, estaban marcadas por el fraude, los resultados se solían conocer antes de la propia elección. "Quién convocaba las elecciones nunca las perdía”.

El mecanismo que se siguió durante toda la Restauración es el siguiente:

a) Al jefe del partido hasta ese momento en la oposición, se le encarga la formación del gobierno, nombrando gobernadores civiles, que se encargarán de preparar las elecciones en sus respectivas provincias con la ayuda y apoyo de los jefes y caciques pertenecientes a su partido político (Organigrama 2).

b) El Gobernador Civil sustituye a los Ayuntamientos, y si se produce algún tipo de problema, el gobernador envía a un Delegado Gubernamental, que suspendía en sus cargos a las autoridades locales, mientras nombraba adictos al

\footnotetext{
${ }^{26}$ Ibidem, p. 46.

${ }^{27}$ BARReda Fontes, J. M. (1986). Caciques y electores. Ciudad Real durante la Restauración (1876-1923). Ciudad Real: I.E.M., p. 57.
} 
partido para ocupar las vacantes y formar una mayoría municipal, que se encargaría de "ganar las elecciones" 28 . En la provincia de Cuenca, en el distrito de Cañete, Martínez de Tejada, diputado a Cortes en 1903, 1905, 1907, 1910 y 1914, mandó al Ministro de la Gobernación un telegrama en el que le da a conocer que el Gobernador Civil envió a Cañete un jefe de orden público como delegado y que nombró a un alcalde: "A pesar de los sinceros deseos de $V$. E. trasmitidos al Gobernador, éste mando á Cañete jefe orden publico como delegado y posesiono ayer alcalde nombrado sin concurso del propietario..."29. El papel desempeñado por la figura del alcalde será fundamental en el juego electoral, como hemos dicho, ya que intervenía activamente en la falsificación de los censos, destitución de interventores pertenecientes a la oposición y cuantas artimañas fuesen necesarias para lograr el objetivo, la victoria electoral, consiguiendo además la plena sumisión de los jueces, imprescindible para tener garantizada la impunidad en los "manejos electorales".

Organigrama 2: Relaciones de poder.

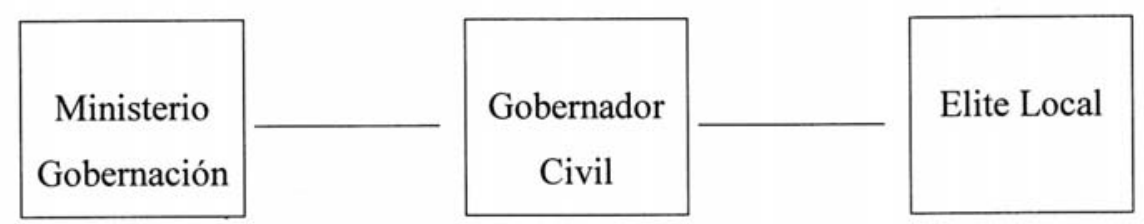

Fuente: GonzÁlez CAlleja, E. y Moreno Luzón, J. (1993). Elecciones y Parlamentarios..., pp. 214-220. Elaboración propia.

c) El gobierno elabora el encasillado, "la esencia del sistema del turno pacífico". El encasillado es la lista de candidatos que designa el gobierno central para que salgan elegidos en las elecciones ${ }^{30}$. Esta operación consistía en la colocación en "casillas" de los candidatos de cada distrito que el gobierno estaba dispuesto a defender o proteger. El encasillado necesitaba de un pacto entre las diferentes fuerzas políticas, necesitaba de un compromiso entre la oligarquía nacional y las oligarquías provinciales y locales, además de un pacto con los partidos de la oposición para que el grupo político que tenía que ganar las elecciones obtuviese la

${ }^{28}$ VARela Ortega, J. (1977). Los amigos políticos..., Cap. 7.

29 AHN, Gobernación, leg 23-A, Caj. 1, Carp. 2, Martínez de Tejada a Ministro de la Gobernación, 20-8-1905.

${ }^{30}$ Varela Ortega, J. (1977). Los amigos políticos..., Cap. 7. 
mayoría en las Cortes. Las negociaciones a nivel provincial y local se llevaban a cabo por medio del representante del poder central en cada provincia, el Gobernador Civil, que buscaba llegar a un acuerdo con los caciques de los distritos para conseguir ajustar los resultados de las elecciones a los deseos del Ministerio ${ }^{31}$.

En el caso de Cuenca, en las elecciones de 1907, el Ministro de la Gobernación, Juan de la Cierva, le envía el encasillado al Gobernador Civil de Cuenca, Ricardo Juárez, en el que decía: "El Gobierno verá con gusto el triunfo de la siguiente candidatura para Diputados á Cortes: Cañete D. Baldomero Martínez de Tejada: Cuenca D. Luis Heraso: Huete Conde de San Luis: Motilla del Palancar D. Jesús Casanova: San Clemente D. J. Martínez Contreras: Tarancón D. Juan Cervantes" $" 32$. Como veremos, sólo uno de los candidatos propuestos, todos adictos al partido gobernante (conservador), no salió elegido diputado a Cortes en las elecciones de ese mismo año. Fue Luis Heraso, el candidato que se presentaba por la capital, y que fue derrotado por el liberal Juan Correcher ${ }^{33}$.

El proceso electoral se resolvía normalmente antes del día de la elección. Aunque el principal objetivo era evitar la lucha entre los dos partidos políticos, no siempre se alcanzaba un acuerdo entre las partes, por lo que había que "forzar la máquina", es decir, ganar de la forma que fuese ${ }^{34}$. Y para ello se recurría a la adulteración de las elecciones. Por tanto, la función que se reservaba al cuerpo electoral era totalmente pasiva ${ }^{35}$. Así, se utilizarán diferentes mecanismos que llevarán al triunfo electoral del partido en el gobierno: la manipulación del censo electoral; el "pucherazo"36, que define cualquier tipo de fraude electoral; sustitución del elector por un agente electoral de uno de los candidatos, ocupando su lugar a la hora de votar; la violencia física, las coacciones económicas y la compra de votos; la práctica de "romper la urna", es decir, cuando en un colegio

31 Tusell, J. (1976). Oligarquía y caciquismo en Andalucía..., Cap. 1.

${ }^{32}$ AC, sec. A, leg. 36-37, encasillado de 1907. V. la reproducción del documento en el Anexo 1.

${ }^{33} \mathrm{AC}$, sec. F, leg. 101, resultados de las elecciones de 1907 en el distrito de Cuenca.

34 GonzÁlez Calleja, E. y Moreno Luzón, J. (1993). Elecciones y Parlamentarios..., p. 219.

${ }^{35}$ PÉrez PicAzo, M ${ }^{\text {a }}$ T. (1996). Historia de España del siglo XX. Barcelona: Ed. Crítica, p. 21.

${ }^{36}$ El "pucherazo" viene de "volcar el puchero", acción cotidiana en la mayoría de las familias que vaciaban el puchero o cocido en un amplio recipiente colocado en el centro de la mesa y del cual los miembros de la familia, sentados alrededor, iban tomando cucharadas o se servían en sus respectivos platos, según la condición social. Volcar el puchero, pues, es darle de comer a alguien, en VARELA ORTEGA, J. (1977). Los amigos políticos..., Cap. 7. 
electoral iba ganando el candidato contrario, se introducía en ella votos de su opositor, etc. ${ }^{37}$.

En Cuenca, alguno de estos procedimientos también se llevó a cabo:

Ladislao Redondo, candidato liberal para diputado a Cortes en el distrito de Huete en 1907, protesta contra la manipulación llevada a cabo por su rival y vencedor en dichas elecciones, el Conde de San Luis, al considerar que en la Sección de Buciegas no se hizo constar en la certificación expedida el número de electos ni votos nulos; en Horcajada de la Torre se consignó en el acta 29 votos al Conde de San Luis, y en la certificación recibida por el alcalde de Huete, 129; o que en la Sección de La Ventosa se verificó la elección a puerta cerrada, y no se dio posesión a los Interventores del candidato liberal, concediéndose además, 182 votos al Conde de San Luis, de 184 del censo ${ }^{38}$.

Vicente Romero Girón, diputado liberal, electo en las legislaturas de 1896, 1898, 1899 y 1901 por el distrito de Cañete, y senador por Cuenca en 1918, 1919 y 1920, critica el "atropello de derechos" por parte de las autoridades locales de Minglanilla (Motilla del Palancar) en 1905: "Pongo en el conocimiento de V. S. Que en el pueblo de Minglanilla se ha celebrado un miting contra las instituciones organizado por el alcalde de aquella localidad habiendose lanzado gritos subversivos..." 39 .

Martínez Contreras, diputado conservador a Cortes en el distrito de San Clemente en 1903, 1905, 1907 y 1910, protesta ante la coacción de Delegados y Guardia Civil y por la compra de votos por parte del candidato liberal: "Ayer me vi sorprendido por una nube de delegados y guardia civil en varios pueblos distintos operando los primeros verdaderas coacciones hubo aqui compra de votos por parte del candidato ministerial...,

En Cubillo (Cañete) las actas de las elecciones municipales de 1905, después de ser suscritas por los interventores fueron alteradas, cambiando totalmente el resultado: “... segun rumores, las actas de eleccion despues de suscritas por los

${ }^{37}$ Ibidem.

${ }^{38} \mathrm{AC}$, sec. F, leg.101, resultados de las elecciones de 1907 en el distrito de Huete (Cuenca).

39 AHN, Gobernación, leg. 23-A, Caj. 1, Carp. 2, Vicente Romero Girón al Ministro de la Gobernación, 30-8-1905.

40 AHN, Gobernación, leg. 23-A, Caj. 1, Carp. 2, Martínez Contreras al Ministro de la Gobernación, 30-8-1905. 
interventores, han sido, adicionadas y alteradas en tal forma que hacen variar por completo el resultado; " 41 .

A pesar de este amplio abanico de métodos fraudulentos, el gobierno, desde el Ministerio de la Gobernación, dice estar dispuesto a impedir que haya compra de votos en las elecciones, y a estimular a las autoridades locales para que averigüen y castiguen a aquellos que cometan tal delito: "Gobierno esta resuelto impedir compra votos y estimulará celo Autoridades para averiguacion y castigo culpables de tan censurable corrupción electoral ${ }^{\prime 42}$. La realidad era otra, como se ha podido comprobar a través de la documentación, el fraude electoral era la nota dominante no sólo en las elecciones conquenses sino en las de toda España.

Pero la pieza fundamental y la clave de los procesos electorales durante la Restauración es el caciquismo ${ }^{43}$. Es el nombre que se le da al entramado de relaciones sociales, clientelares que definían la vida política durante esta época. Unas relaciones que no eran nada igualitarias, en las que se intenta poner en relación al mundo urbano con el rural, es decir, el mundo donde se toman las decisiones políticas con el de la mayor parte del país ${ }^{44}$. Cuando se habla de caciquismo, se habla de la extensa red que se extiende por toda España entrelazada por intereses, pactos y favores, por ello hay que hablar de varios caciques, y no de uno sólo. Se pueden distinguir tres clases de caciques: el de altura o de Corte, el provincial y el rural. Los tres están totalmente interrelacionados ${ }^{45}$. Además, el caciquismo comporta diferentes rasgos, dependiendo del medio geográfico y regional en el que se desenvuelve, es decir existen también diferentes tipos de caciquismo $^{46}$.

El cacique es quién da nombre al sistema político, es quién ejerce el control de la vida pública local ${ }^{47}$. Su poder no reside exclusivamente en la riqueza personal sino también, en el control de la Administración y de la justicia. Su objetivo es el

${ }^{41}$ ADPC, expediente 286, sec. $1^{\mathrm{a}}$, carta de un interventor de Cubillo a la Comisión Provincial de Cuenca, 1905.

42 AHN, Gobernación, leg. 23-A, Caj. 1, Carp. 2, Ministerio de la Gobernación a Vicente Buendia, 2-9-1907.

${ }^{43}$ Pérez Picazo, M ${ }^{\text {a }}$ T. (1996). Historia de España del siglo XX..., p. 26.

${ }^{44}$ González Calleja, E. y Moreno Luzón, J. (1993). Elecciones y Parlamentarios..., p. 219.

${ }^{45}$ VARELA ORTEGA, J. (1977). Los amigos políticos..., p.353.

${ }^{46}$ Tusell, J. (1976). Oligarquía y caciquismo en Andalucía..., p. 551.

${ }^{47}$ García QueIPo De Llano, G. (1996). «Historia de España. El reinado de Alfonso XIII. La modernización fallida». Historia 16, p. 10. 
control político, que viene dado por la desmovilización ideológica del electorado ${ }^{48}$. La figura del cacique emerge como la del terrateniente, controlando la comunidad rural $^{49}$. Como dice Tuñón de Lara, "es el señor omnímodo"s0. En la provincia de Cuenca se pueden nombrar algunos caciques con gran relevancia como: Mariano Catalina, perteneciente al partido conservador, diputado a Cortes en 1884 y senador del reino por las provincias de Cuenca (1896-1898 y 1903-1904) y Guadalajara (1900-1901 $)^{51}$; Baldomero Martínez de Tejada, "afiliado al partido conservador, ha organizado y disciplinado de tal modo las fuerzas de esa agrupación política en el distrito de Cañete, que en los tiempos de más ruda oposición les lleva al combate y obtiene con ellas el triunfo" ${ }^{2}$; Vicente Romero Girón, electo en las legislaturas de 1896, 1898, 1899 y 1901 por el distrito de Cañete, y senador en Cuenca en 1918, 1919 y $1921^{53}$; Fernando Sartorius, Conde de San Luis, también conservador, que dominó de forma absoluta el distrito de Huete, por el que obtuvo el acta de diputado al Congreso doce veces entre 1896 y 1921, siendo este último año nombrado senador vitalicio. Se le llegó a conocer como el "gran señor de Cuenca" $^{, 54}$.

El entramado caciquil, al extenderse por toda España, se puede llegar a pensar que es desde Madrid, la sede del poder central, desde donde se articula todo este entramado, ya que allí se hace el pacto entre los dos partidos turnantes para poner en funcionamiento los mecanismos electorales ${ }^{55}$. Pero también es posible, como en el caso de Cuenca, que se conceda la preeminencia política a las fuerzas locales,

\footnotetext{
48 Ibidem; González Calleja, E. y Moreno Luzón, J. (1993). Elecciones y Parlamentarios..., p. 213.

49 GonzÁlez Calleja, E. y Moreno Luzón, J. (1993). Elecciones y Parlamentarios..., p. 212.

${ }^{50}$ TuÑón De LARA, M. (1975). Historia y realidad del poder. El poder y las "elites" en el primer tercio de la España del siglo XX. Madrid: Edicusa, pp. 44-45.

${ }^{51}$ Vallejo Y Guijarro, M. L. (1977). Glorias conquenses. Cuenca: Imprenta de la Excma. Diputación Provincial, p.131; Priego Sánchez-Morate, H. y Silva Herranz, J. A. (2002). Diccionario de personajes conquenses (nacidos antes del año 1900). Cuenca: Diputación Provincial, pp. 96-97.

52 SÁnchez De Los SAntos (1911). Las Cortes españolas de 1910. Tipografía Antonio Marzo, Madrid, p. 655.

53 González Calleja, E. y Moreno Luzón, J. (1993). Elecciones y Parlamentarios..., p. 217.

54 Priego Sánchez-Morate, H. y Silva Herranz, J. A. (2002). Diccionario de personajes conquenses..., pp. 351-352.

55 Es lo que define Tusell al describir el "encasillado", en TuSELl, J. (1976). Oligarquía y caciquismo en Andalucía..., p.25.
} 
debido a su arraigo en los respectivos distritos ${ }^{56}$.En un telegrama oficial del Gobernador Civil de Cuenca al Ministro de la Gobernación en 1905 se puede observar como la presión del poder local es muy importante en la provincia, más que la del propio poder central: "Emisario confianza Catalina dice que si V. Girón no se retira de Cañete presentará candidatos para Motilla y Cuenca que derroten á Girón y Ballesteros, y que formará candidatura cerrada para Senadores..."

\section{LOS PROCESOS ELECTORALES EN LA PROVINCIA DE CUENCA}

El proceso electoral conquense de principios del siglo XX estuvo marcado por el fraude electoral y por los manejos políticos de ciertos caciques, especialmente Mariano Catalina. Éste, junto al Conde de San Luis controlaban la provincia, y al contrario que en el resto de Castilla-La Mancha, donde el cunerismo adquiría una gran fuerza, en Cuenca el control político estaba en manos de la élite local, aunque sí es cierto que existían ciertos políticos foráneos y que desde el Gobierno Central se enviaban delegados gubernativos para guardar el orden público ${ }^{58}$.

A la vista del Cuadro 4 se puede observar que alrededor de un $25 \%$ de la población de la provincia de Cuenca tuvo derecho a voto, y entre éstos es significativo resaltar el bajo porcentaje de abstenciones, alrededor del $20 \%$, exceptuando algunos distritos como Huete en 1903 y 1907, con un 32,6\% y un $30 \%$ respectivamente; o Tarancón, que en las elecciones de 1907 cuenta con un $50 \%$ de abstención.

El 8 de marzo de 1903 los resultados electorales fueron de 230 escaños para los conservadores y 93 para los liberales, aunque en algunas zonas del país, como Cataluña, Levante, Aragón, Navarra y País Vasco se produjo un retroceso de los conservadores en beneficio de los republicanos. Este resultado fue objeto de un enérgico reproche de Alfonso XIII a Maura, Ministro de la Gobernación, por su proclamada "honradez electoral".

${ }^{56}$ Es la postura de Emile Temime y Gèrard Chastagnaret (1978). «Contribution à l'etude des sources et des formes des pouvoirs locaux dans l'Espagne contemporaine. Reflexions sur le caciquismo» en Cahiers de la Mediterranée.

57 AHN, Gobernación, leg. 23-A, Caj. 1, Carp. 2, Gobernador Civil al Ministro de la Gobernación, 29-8-1905.

${ }^{58}$ Moreno LuZÓn, J. (2001).«“Castilla-La Mancha»..., p. 151. 
Cuadro 4: Censo electoral y abstención en las elecciones de 1903, 1905 y 1907

\begin{tabular}{|c|c|c|c|c|c|c|c|c|c|}
\hline$A$ & & 1903 & & & 1905 & & & 1907 & \\
\hline$B$ & 1 & 2 & 3 & 1 & 2 & 3 & 1 & 2 & 3 \\
\hline Cuenca & & 10.103 & 14,6 & & 10.966 & 17,3 & 44.638 & 10.998 & 24,0 \\
\hline Tarancón & & 10.680 & 19,9 & & 10.838 & 25,9 & 41.428 & 10.894 & 50,0 \\
\hline S.Clemente & & 10.058 & 15,5 & & 10.299 & 12,8 & 40.455 & 10.359 & 21,0 \\
\hline M.Palancar & & 10.683 & 13,0 & & 11.078 & 15,1 & 41.474 & 11.079 & 24,0 \\
\hline Cañete & & 10.716 & 17,2 & & 11.047 & 27,4 & 42.883 & 11.225 & 15,0 \\
\hline Huete & & 10.158 & 32,6 & & 10.320 & 16,7 & 39.877 & 10.371 & 30,0 \\
\hline CUENCA & 249.696 & 62.398 & 18,7 & 250.755 & 64.548 & 19,3 & 250.755 & 64.927 & $20,8 \%$ \\
\hline
\end{tabular}

A, años electorales; B, provincia y circunscripción electoral; 1, Población total; 2, Censo electoral; 3, Abstención (\%).

Fuente: GonzÁlez Calleja, E. y Moreno Luzón, J. (1993). Elecciones y Parlamentarios..., pp. 110-114. Elaboración propia.

Cuadro 5: Candidatos para Diputados a Cortes en las elecciones de 1903

\begin{tabular}{lcc}
\hline \multicolumn{1}{c}{ Distritos } & Candidato conservador & Candidato liberal \\
\hline Cuenca & Pedro José Cobo* & Rafael Piquer \\
$\begin{array}{l}\text { Cañete } \\
\text { Huete }\end{array}$ & B. Martínez de Tejada* & Vicente Romero Girón \\
$\begin{array}{l}\text { Motilla del Palancar } \\
\text { San Clemente }\end{array}$ & Conde de San Luis* & \\
Tarancón & Antonio Tendero* & Fco. Martínez García \\
\hline Fco. Martínez Contreras* & \\
\hline
\end{tabular}

*Proclamados

FUENTE: AC, sec F, leg. 101, resultados de las elecciones de 1903 en Cuenca. Elaboración propia.

En el caso castellano-manchego continuó el predominio de candidatos conservadores en el poder, salvo en Guadalajara, que desde este momento se convertirá en feudo del liberal Conde de Romanones ${ }^{59}$. Por lo que respecta a Cuenca, fueron proclamados los candidatos conservadores con amplia mayoría, siendo notoria la derrota liberal, como se puede apreciar en el Cuadro 5.

Para conocer el proceso de proclamación de estos candidatos resulta significativa la correspondencia mantenida entre Antonio Maura y Mariano Catalina, donde propone los candidatos convenientes. Se puede advertir como Mariano Catalina cierra el conflictivo distrito de Cañete apoyándose en el conservador Martínez de Tejada en la lucha con el candidato liberal, Vicente Romero Girón; como impone a José Cobo presentarse para la candidatura de la

\footnotetext{
${ }^{59}$ GonzÁlez Calleja, E. y Moreno Luzón, J. (1993). Elecciones y Parlamentarios..., pp. 9495.
} 
capital; a la vez que inducía al conservador Tendero para ser proclamado Diputado a Cortes, el cual tenía una afiliación conservadora y parentesco con Mariano Catalina: "Ayer tuve una conferencia con Catalina y le encontré resuelto a no admitir mi candidatura por la Capital. A Jose Cobo su pariente está dispuesto a imponerle que sea el candidato, contra su deseo de ir al Senado...Haberme cerrado el distrito de Cañete con el compromiso de Martínez de Tejada... haber inclinado indirectamente a Tendero que se presente por Motilla..."60. Vemos entonces como el control político de Mariano Catalina provocaron la derrota de los liberales en los distritos de Cañete, Cuenca y Motilla del Palancar. En cuanto a los candidatos al Senado, fueron propuestos por Catalina: el conservador Risueño y José Cobo, dejando un tercer candidato a designio del gobierno, lo que confirma el peso del poder local.

El fraude electoral también se puede observar en las elecciones municipales de 1903: en el distrito de San Clemente se produjo una protesta contra extralimitaciones e ilegalidades de los vocales de la Junta Municipal del Censo, donde algunos pidieron ser proclamados candidatos como ex - concejales. Esto invalidaba el acto de proclamación de candidatos y designación de Interventores, por lo que serían nulas las actas posteriores de la elección ${ }^{61}$.

El 10 de septiembre de 1905 el partido liberal, encabezado por Montero Ríos, superviviente del Sexenio, obtuvo la victoria electoral con 229 escaños por 96 de los conservadores. Pero las divisiones internas del partido liberal convirtieron en fugaces los gobiernos liberales (Montero Ríos, Moret, López Domínguez...), poniendo de manifiesto el problema de liderazgo y la desunión creciente entre éstos ${ }^{62}$.

A pesar de la mayoría liberal en las elecciones generales, en Cuenca continua habiendo una mayoría conservadora, exceptuando los distritos de Cuenca y Motilla del Palancar, como se puede observar en el Cuadro 6.

Incluso en la elección de los senadores la mayoría es conservadora. Fueron elegidos José Cobo Jiménez y Tomás Montejo y Rica como senadores

${ }^{60}$ AM, leg. 174/17, Diputado a Cortes a Antonio Maura. 1903.

${ }^{61} \mathrm{ADPC}$, expediente 681 , sec. $1^{\mathrm{a}}$, expediente de las elecciones municipales y reclamaciones de San Clemente, remitido por el alcalde, 1903.

62 González Calleja, E. y Moreno Luzón, J. (1993). Elecciones y Parlamentarios..., pp. 9495. 
conservadores, y Gregorio Alonso Grimaldi como senador adicto ${ }^{63}$.

Cuadro 6: Candidatos para Diputados a Cortes en las elecciones de 1905

\begin{tabular}{lcc}
\hline \multicolumn{1}{c}{ Distritos } & Candidato conservador & Candidato liberal \\
\hline Cuenca & Luis Heraso & A. Ballesteros Rubio* \\
Cañete & B. Martínez de Tejada* & Vicente Romero Girón \\
Huete & Conde de San Luis* & Ladislao Redondo \\
$\begin{array}{l}\text { Motilla del Palancar } \\
\text { San Clemente }\end{array}$ & Manuel Romero Girón & Fco. Martínez García* \\
Tarancón & Fco. Martínez Contreras* & Constantino Careaga \\
*Pan Cervantes* & Vicente Buendia \\
$\begin{array}{l}\text { FuENTE: AC, sec F, leg. } \\
\text { Elaboración propia. }\end{array}$ & & \\
\end{tabular}

El poder de la influencia de Mariano Catalina continuó siendo muy importante, ya que a pesar de la proclamación de los liberales Francisco Martínez García y Arturo Ballesteros en los distritos de Motilla del Palancar y Cuenca respectivamente, los restantes distritos siguieron siendo liderados por los conservadores.

Aunque la ley electoral de 1890 tipifica como delito el fraude electoral y en 1905 el Ministro de la Gobernación dice estar dispuesto a impedir que haya compra de votos en las elecciones, estimulando a las autoridades para que averigüen y castiguen a los culpables- "Gobierno está resuelto impedir compra votos y estimulará celo Autoridades para averiguacion y castigo culpables de tan censurable corrupción electoral "64-, se puede afirmar a la vista de la documentación examinada, que la realidad estaba muy alejada de la trasparencia pretendida: la violación de derechos por parte de las autoridades a las instituciones: “... en el pueblo de Minglanilla se ha celebrado un miting contra las instituciones organizado por el alcalde de aquella localidad habiendose lanzado gritos subversivos: Mis amigos se vieron atropellados en sus derechos por las autoridades locales..." elección, después de suscritas por los interventores, han sido, adicionadas y

${ }^{63}$ AHN, Gobernación, leg. 22-A, Exp. 9. Lista de senadores.

${ }^{64}$ AHN, Gobernación, leg. 23-A, Caj. 1, Carp. 2, Ministro de la Gobernación a Vicente Buendía en Tarancón, 2-9-1905.

65 AHN, Gobernación, leg. 23-A, Caj. 1, Carp. 2, Vicente Romero Girón al Ministro de la Gobernación, Motilla del Palancar, 30-8-1905. 
alteradas en tal forma que hacen variar por completo el resultado;..." "66; las coacciones y amenazas: "Con toda energía e indignadísimo protesto solemnemente ante V.S. Sobre coacciones, amenazas, atropellos y conducta incalificable distrito de Cañete..."67; y la sustitución de alcaldes por personas que nombraba el Gobernador Civil: "A pesar de los simeros deseos de V. E. Trasmitidos al Gobernador este mando a Cañete jefe de orden publico como delegado y posesiono ayer alcalde nombrado sin concurso del propietario..." ${ }^{\text {"68 }}$, fueron las claves del proceso electoral de 1905 en Cuenca.

Las elecciones del 21 de abril de 1907, con Juan de la Cierva como Ministro de la Gobernación, propiciaron una abrumadora victoria del partido conservador (252 escaños $)^{69}$.

Esta victoria favoreció al partido conservador en Cuenca, como se puede observar en el Cuadro 7, ya que salvo en su capital, donde se mantuvo un diputado liberal, Juan Correcher, en el resto de distritos obtendrán la victoria los conservadores. Hasta 1905 en la capital conquense se había respetado el turno de partidos, pero con Juan Correcher el distrito de Cuenca será dominado por el liberal hasta 1918.

En estas elecciones llama la atención la disputa en el distrito de Huete entre el liberal Ladislao Redondo y el conservador Fernando Sartorius, Conde de San Luis: el liberal protestó el Acta de escrutinio general, acusando de acciones fraudulentas al candidato conservador: en la sección de Buciegas no se hizo constar en la certificación expedida el número de electos ni papeletas nulas; en Horcajada de la Torre se consignó en el acta 29 votos al Conde de San Luis, y en la certificación recibida por el alcalde de Huete, 129; en Baldemoro del Rey por aparecer dos actas, una presentada por el Alcalde de Huete sin consignar los votos de cada candidato y otra presentada por un interventor autorizado donde se dan 99 votos al Conde de San Luis y ninguno a Redondo; en la sección de La Ventosa se verificó

${ }^{66}$ ADPC, expediente 286, carta de un interventor de Cubillo a la Comisión Provincial, 1905.

67 AHN, Gobernación, leg. 23-A, Caj. 1, Carp. 2, Martínez de Tejada al Ministro de la Gobernación, Huete, 24-8-1905.

68 AHN, Gobernación, leg. 23-A, Caj. 1, Carp. 2, Martínez de Tejada al Ministro de la Gobernación, Cuenca, 20-8-1905.

${ }^{69}$ Gutierrez Lloret, R. A. y Zurita, R. (2001). «El encasillado en las elecciones de la España de la Restauración: Murcia y el País Valenciano en 1907». Historia Contemporánea, 22, pp. 316-330. 
la elección a puerta cerrada, y no se dio posesión a los interventores de Redondo, concediendo éste además, 182 votos al Conde de San Luis, de 184 del censo ${ }^{70}$.

Cuadro 7: Candidatos para Diputados a Cortes en las elecciones de 1907

\begin{tabular}{lcc}
\hline \multicolumn{1}{c}{ Distritos } & Candidato conservador & Candidato liberal \\
\hline Cuenca & Luis Heraso & Juan Correcher* \\
Cañete & B. Martínez de Tejada* & \\
Huete & Conde de San Luis* & Ladislao Redondo \\
Motilla del Palancar & Jesús Casanova* & Pompeyo Vidal \\
San Clemente & Fco. Martínez Contreras* & \\
Tarancón & Juan Cervantes* & Vicente Buendia \\
\hline
\end{tabular}

*Proclamados

FUENTE: AC, sec F, leg. 101, resultados de las elecciones de 1907 en Cuenca. Elaboración propia.

En el distrito de Cuenca se enfrentaron el liberal Juan Correcher y el conservador Luis Heraso. El candidato conservador, tras su derrota electoral, reprochó al liberal que su proclamación debería ser nula por dos razones: 1) por la falta de presencia de conservadores en la mesa electoral, lo que engendró una serie de tensiones en el salón de escrutinio, lugar que tuvo que abandonar Heraso. 2) porque la coacción y la violencia fueron notorias ${ }^{71}$.

Los candidatos conservadores acusaron a los liberales de forma reiterada de los "manejos desleales" que éstos llevaron a cabo para conseguir votos: "Por denuncias hechas ayer en el periódico de la localidad titulado "Las Noticias" sobre soborno y corrupción sufragios por candidato liberal en el pueblo de La Parrilla de este distrito. "72

En resumen, se puede decir que, la práctica política de los partidos dinásticos dejaba entrever las limitaciones democratizadoras en aquellas zonas, como es el caso conquense, en las que la actividad política se asentaba en el dominio de las relaciones clientelares. El protagonismo político se venía experimentando desde comienzos del siglo XX, consecuencia del agotamiento del propio sistema de turno, ya desde la crisis del 98, en provincia de Cuenca pervivieron las redes personales del poder local, plenamente apegadas a la vieja política con toda su

\footnotetext{
${ }^{70}$ AC, sec. F, leg. 101, protestas de Ladislao Redondo al Conde de San Luis, Huete, 1907.

${ }^{71}$ AC, sec. A, leg. 39, Gobernador Civil al Ministro de la Gobernación, 26-4-1907.

72 AHN, leg. 24-A, Caj. 2, Carp. 12, el Gobernador Civil al Ministro de la Gobernación, 11-4-
} 1907. 
carga caciquil, clientelar y elitista. El "pacto" como fórmula política y el "mecanismo del favor" fueron elementos enormemente enraizados en la sociedad.

Los primeros y muy tímidos intentos de movilización social, no llegarán a la provincia de Cuenca hasta 1909, al unirse liberales y republicanos para contestar a la política derechista de Maura. Por consiguiente podemos afirmar que, esta provincia castellano-manchega fue uno de los puntos de la geografía española en donde más tiempo pervivieron las estructuras arcaicas y el paso a la modernidad resultó mucho más lento que en otras zonas de España. 
